\title{
Bucket-handle tear of posterior uterine cervical lip in a second-trimester unscarred uterus after use of misoprostol: A first report of two cases
}

\author{
S R Singhal, ${ }^{1} \mathrm{MD} ; \mathbf{S}$ K Singhal, ${ }^{2} \mathrm{MD}$ \\ ${ }^{1}$ Department of Obstetrics and Gynaecology, Pandit Bhagwat Dayal Sharma Post Graduate Institute of Medical Sciences, Rohtak, Haryana, India \\ ${ }^{2}$ Department of Anaesthesiology, Pandit Bhagwat Dayal Sharma Post Graduate Institute of Medical Sciences, Rohtak, Haryana, India
}

Corresponding author: S R Singhal (savita06@gmail.com)

\begin{abstract}
A bucket-handle tear is a laceration of either the anterior lip or the posterior lip of the cervix so that it hangs like the handle of a bucket. These cervical injuries are more common in term deliveries and are associated with various risks factors, including cervical cerclage, induction of labour, young maternal age, assisted vaginal delivery, prostaglandin use and precipitate labour. We came across two patients who experienced a bucket handle tear of the posterior lip of the cervix in second-trimester abortions due to prostaglandin $\mathrm{E}_{1}$ use. Such a case has not been reported in the literature. In this case study, we report two such cases.
\end{abstract}

S Afr J Obstet Gynaecol 2017;23(2):71-72. DOI:10.7196/SAJOG.2017.v23i2.1177

Cervical injuries are not uncommon during labour and abortion. Reported cervical injuries include cervical lacerations, lateral cervical tears, bucket-handle tears and annular detachment of the cervix. ${ }^{[1]} \mathrm{A}$ bucket-handle tear is a laceration of the anterior or the posterior lip of the cervix so that it hangs like the handle of a bucket. Although these cervical injuries are more common in term deliveries, alternative risk factors associated with cervical injuries are cervical cerclage, induction of labour, young maternal age, vacuum-assisted vaginal delivery, prostaglandin use and precipitate labour. ${ }^{[2,3]}$ We examined two patients who each had a bucket-handle tear of the posterior lip of cervix in their secondtrimester abortions due to the use of prostaglandin $\mathrm{E}^{1}$. This has not been reported in literature.

\section{Case 1}

A 26-year-old $\mathrm{G}_{4} \mathrm{P}_{1} \mathrm{~A}_{2}(\mathrm{G}=$ no. of pregnancies; $\mathrm{P}=$ no. of delivered pregnancies; $\mathrm{A}=$ no. of abortions) at 19 weeks of pregnancy was admitted with a complaint of abdominal pain and 2 days of bleeding per vaginam. She had had one full-term vaginal delivery without any complications 3 years previously, and two spontaneous miscarriages at 2 months gestation, which had not been followed by evacuation. In this case, on examination the uterus was 22 weeks in size, tense, tender and fetal parts were not palpable. Ultrasound revealed a dead fetus of 18 weeks' gestation with a retroplacental clot of $10 \times 9 \mathrm{~cm}$. Augmentation of abortion was undertaken with $200 \mu \mathrm{g}$ of misoprostol administered vaginally at 4-hour intervals. The patient aborted a $300 \mathrm{~g}$ abortus with $300 \mathrm{~mL}$ of blood clots present posterior to the placenta after four doses of misoprostol. The patient bled excessively after the abortion.

On per vaginam and bimanual examination the uterus was well contracted. The cervix was examined in detail. The cervical os was found to be only $2 \mathrm{~cm}$ dilated and there was a $4 \mathrm{~cm}$ tear in the posterior cervical lip, which was bleeding, suggesting that the patient had aborted through the tear (Fig. 1). The defect was repaired with chromic catgut sutures. The patient had an uneventful recovery following the abortion.

\section{Case 2}

A 23-year-old primigravida presented at 18 weeks' gestation for medical termination of pregnancy for fetal hydrocephalus and meningomyelocele. She was given $200 \mu \mathrm{g}$ of mifepristone vaginally and after 48 hours, $400 \mu \mathrm{g}$ of misoprostrol was administered vaginally at 4 -hourly intervals. After four doses of misoprostol, the cervix was still one-finger dilated and 50\% effaced. Two more

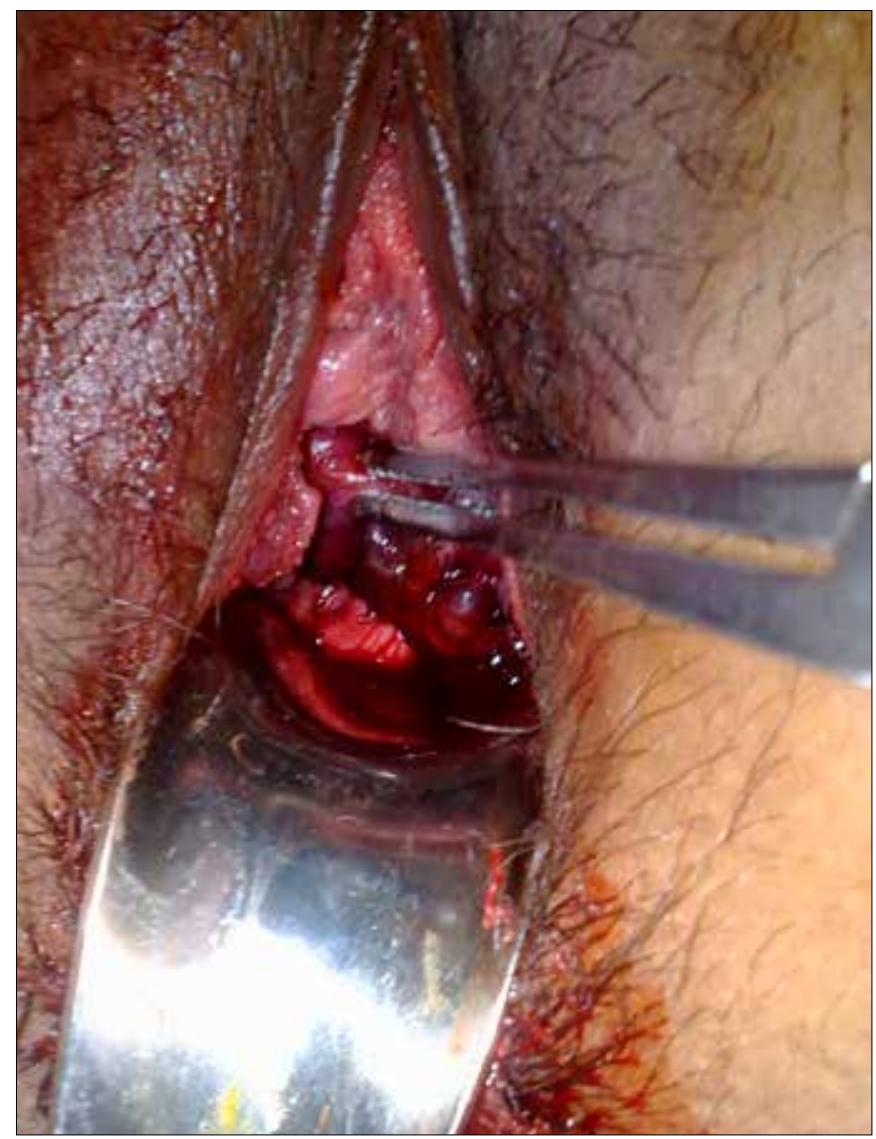

Fig.1. Transverse cervical tear on posterior lip of cervix. 
doses were given and the patient aborted a $250 \mathrm{~g}$, dead, congenitally malformed abortus after six doses of misoprostol. The placenta was expelled completely. After the abortion, the patient had excessive bleeding. A per vaginam examination was done, which revealed that the cervical os was $\sim 2 \mathrm{~cm}$ dilated and there was a $3 \mathrm{~cm}$ cervical tear on the posterior lip of the cervix, which was bleeding and through which the fetus had possibly aborted. The tear was stitched with chromic catgut sutures.

\section{Discussion}

The cause of a bucket-handle tear may be an unyielding cervix due to fibrosis or stenosis, leading to pressure being transferred either to the anterior or posterior lip of the cervix. An added factor may be hypertonus caused by prostaglandins. ${ }^{[4]}$ Cervical lacerations are common at term pregnancy. In the first case, the patient had a history of two abortions and one delivery. This led to fibrosis of the cervix, causing pressure on the posterior cervix which yielded to the uterine contractions, leading to the bucket-handle tear. In the second case, the patient was primigravida and the cervix was only one finger dilated after four doses of misoprostol despite good uterine contractions. The cervix might have been congenitally stenosed, causing it not to yield to uterine contractions, or there may have been a history of unconfessed early pregnancy losses. In both patients, the cervical os was $2 \mathrm{~cm}$ dilated after the abortion, favouring the aetiology of a rigid cervix. The patients most likely aborted through the tear in the posterior lip of the cervix. The patients were fortunate that contractions did not eventually lead to uterine rupture - another serious complication of the unyielding cervix.

There are clear-cut guidelines for managing a rigid cervix in term pregnancies, but this aspect of cervical stenosis is not taken into account at lower gestational ages. For mid-trimester abortions, further doses of prostaglandins should be withheld if the cervix is not dilating in spite of good uterine contractions to avoid unusual cervical tears.

\section{Conclusion}

In second-trimester abortions induced with prostaglandins, if the cervix is not yielding despite good uterine contractions, there is an option to withhold further doses to avoid cervical injuries.

Acknowledgement. None.

Author contributions. Both authors jointly carried out the study, compiled, analysed and prepared the manuscript.

Funding. None.

Conflict of interest. None.

1. Parikh R, Brotzman S, Anasti IN. Cervical laceration: Some surprising facts. Am J Obstet Gynecol 2007;196(5):e17-e18. https://doi.org/10.1016/j.ajog.2006.11.043

2. Melamed N, Ben-Haroush A, Chen R, Kaplan B, Yogev Y. Intrapartum cervical lacerations: Characteristics, risk factors, and effect on subsequent pregnancies. Am J Obstet Gynecol 2009;200(4):388.el-4. https://doi.org/10.1016/j.ajog.2008.10.034

3. Landy HJ, Laughon SK, Bailit JL, Kominiarek MA, Gonzalez-Quintero VH, Ramirez M. Characteristics associated with severe perineal and cervical lacerations during vaginal delivery. Obstet Gynecol 2011;117(3):627-635. https://doi.org/10.1097/aog.0b013e31820afaf2

4. Premi HK, Sood R, Gupta T, Sood A. Bucket handle tear of cervix following prostaglandin instillation. The Antiseptic 1998;95(6):191. 